DOI: http://doi.org/10.21698/simi.2018.fp16

\title{
SEEDLINGS PLANTING INNOVATIVE TECHNOLOGY DEDICATED FOR SLOPE DEGRADED TERRAINS AND HARD ENVIRONMENTAL CONDITIONS
}

\author{
Constantin Gabriel Bogdanof $^{1}$, Alexandra Liana Visan ${ }^{1}$, Dumitru Milea ${ }^{1}$, Radu Ciuperca ${ }^{1}$, \\ Alexandru-Ionut Petrisor ${ }^{2}$ \\ ${ }^{1}$ INMA Bucharest, 6 Ion Ionescu de la Brad Blvd., 013813, Bucharest, gbogdanof@gmail.com, \\ Romania \\ ${ }^{2}$ Ion Mincu University of Architecture and Urban Planning, 010014, 18-20 Academiei, \\ district 1, Bucharest, alexandru.petrisor@incd.ro, Romania
}

\begin{abstract}
This paper aims to present a seedling planting innovative technology developed to achieve forestation and rehabilitation works of degraded slope lands. Form the experimental data obtained from testing activity conducted to conclusion that the designed equipment's are adequate and comply with the specific works requirements, namely in heavy environmental conditions (degraded soil processing, levelling and terrace surface modelling, planting settlement, etc.). This technology answers to the need to implement measures of environmental rehabilitation (namely restoration/ establishment of green infrastructure) and enhancement of slopedegraded forestlands. The innovation element consists in development of several adaptable equipment's to the real working conditions (land stability, terrace dimensions, type of power source and seedlings planting variety) in order to achieve the highest performances and to respect labour safety standards. This technology raises the mechanization performance of forestry and pomiculture works with impact on soil remediation, lowering the surface and depth erosion degree, capitalization of rainwater, lowering the dust pollution and natural calamity risk and the rehabilitation of inland flora. Appling this innovative technology within environmental management process can conduct to a good cost-benefit analysis that has a great impact on medium and long time by lowering the calamity risks and the threads of entire populations and local species.
\end{abstract}

Keywords: degraded terrains, environment improvement, green infrastructure, planting technology, soil remediation

\section{Introduction}

Attempting to reconcile man and environment, the concept of sustainable development, was defined by Brundtland and involves a balanced integration of three traditional pillars: economy, society and environment. Due to their interconnectivity the sustainable development requires three actions: environmental policies design to internalize the environmental costs based on assessing the potential impact of human activities; natural areas conservation as protected areas and ecological restoration of degraded systems. Nowadays the restoration of degraded ecosystems is provided by the" ecosystem services”, this concept represents the benefits offered by ecosystems to the human society (Zakri \& Watson 2003, Watson \& Zakri 2005, Young 2010). Ecosystem services have economic, 


\section{INTERNATIONAL SYMPOSIUM "THE ENVIRONMENT AND THE INDUSTRY", SIMI 2018, PROCEEDINGS BOOK}

social, cultural, and insurance value, in addition to the environmental include air purification, noise reduction, urban cooling, and runoff mitigation (La Greca et al 2011, Gómez-Baggethun \& Barton 2013). The importance of forests lies in the multitude of ecosystem services provide: an improvement of microclimate (habitat, low pollination, or protection against floods and landslides), air quality and water, as well as cultural and supporting services (Jim \& Chen 2009, Petrisor 2015). Despite their ecological value, worldwide forests disappear at increasing rates due to the deforestation (Andronache et al 2016). The latest Romania studies has indicated that deforestation represent a threat to forest ecosystems during the transition period (Popovici et al 2013, Petrisor 2015, Petrisor \& Petrisor 2017). This issue is common to transition countries and constitutes a consequence of land restitution (Kuemmerle et al 2007, Müller \& Munroe 2008, Knorn et al 2012, Kupková et al 2013). The international experience indicates, that the only way to mitigate the forest loss is to restore the forests on degraded lands, fact that lead to ecosystem restoration (Chazdon 2008). The forests restoration can be achieved by two processes, afforestation and reforestation, (afforestation is conversion of other land-uses into forest, while reforestation is re-establishment of forest formations), and in these cases the canopy covers more than $10 \%$ through plantations/natural regeneration and less than $10 \%$ due to human-induced or natural perturbations (Dutca \& Abrudan 2010).

In order to accomplish a proper green infrastructure on slope degraded lends, first of all it must be established the trees specialists and panting density. Using the appropriate planting methods must be achieved appropriate landscaping works to establish adequate vegetation in accordance with site specific flora and fauna and also to reduce erosion processes (Pop 2012). From the technological point of view, the most suitable landscaping works are the terracing works, because the meteorological precipitations are drained and directed towards established plants root system, whose role is to absorb the excessive moisture and assure the appropriate conditions to develop them. Fact that will improve the microclimate by, stabilizing the soil; preventing ravines and landslide generation and stopping the wind erosion.

In practice, was proven, that the most efficiently terraces are those with counterslope platform of $15^{0}$ and $0.6 \div 1.5 \mathrm{~m}$ width, alternated with shredded strips, especially for humidity deficit mountain slopes. In this case, the precipitations are absorbed by the shredded strips and assures the water necessary for forestry seedlings. In accordance with rainfall quantity is chosen the strip with; the number of seedlings planted and also the terrace counter-slope. Also, was proven that the water quantity that can be retained is of $17 \mathrm{l} / \mathrm{m}^{-2}$ (for a counter-slope of $10 \%$ ) and $25 \mathrm{l} / \mathrm{m}^{-2}$ (for a counter-slope of $15 \%$ ). If it is taken in to consideration also the water infiltrations from the terrace surface it can be archived a total rainfall retention of approx. $20 \div 40 \mathrm{l} / \mathrm{m}^{-2}$, especially if the terraces counter-slopes are periodically maintained (Untaru 2010).

\section{Materials and Methods}

The innovative technology developed by INMA institute, is sustainable because can be easily used and adapted to establish a wide range of green infrastructure (forestry seedling requirements), with terrain geographical type (terrace dimensions and structure, climatic and soil factors) and afforestation scheme, Figure 1. For degraded 


\section{INTERNATIONAL SYMPOSIUM "THE ENVIRONMENT AND THE INDUSTRY", SIMI 2018, PROCEEDINGS BOOK}

lands the infrastructure must be composed mainly form trees altered with arboretum and this species, must be chosen so that: to be resistant to severe weather conditions (especially drought); less demanding from the ground; to have a vigorous growth; a well distribution on the ground; to not have common diseases; to produce rich litter; to regenerate easily and naturally; to produce valuable wood, etc. Normally, the work process begins from upstream to downstream, respectably from the confluence area to the main collector.

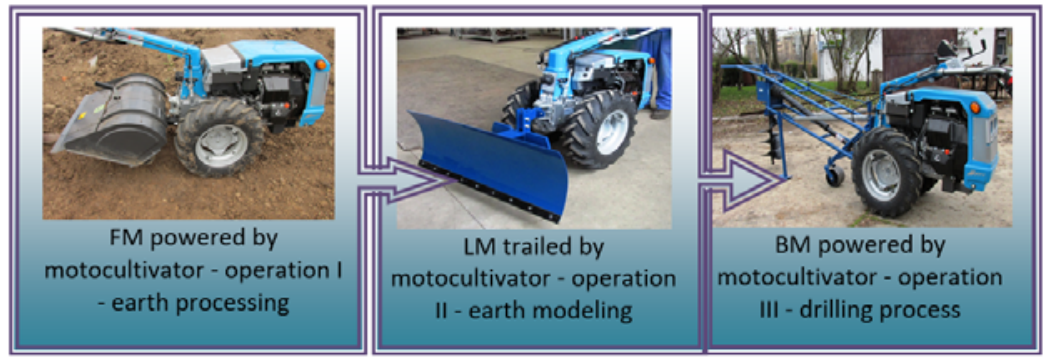

Figure 1. Technologic process of seedlings planting innovative technology

The innovation consists in using a small gauge power source, namely 318 Bertolini motocultivator of $19 \mathrm{HP}$, that will be equipped with a succession of equipment's designed to work in difficult soil conditions (unstable or compacted soils; reduced working space, high inclination, etc.), as: a horizontal milling equipment for soil processing - FM; a soil modelling equipment with levelling blade - LM and also an innovative drilling equipment that generate seedling dwelling - BM.

From technological point of view the FM is used to loosen and grinding the soil, fact that will allow to be easily modeled the terrace surface using the LM (designed to generate the counter-slope inclination). In cases when the counter-slope is more then $15^{0}$, it is required to be used the FM again, in order to improve the soil permeability. The BM equipment has been designed to generate vertical holes indifferent of terrace counter slope inclination $\left(\leq 30^{\circ}\right)$, fact that will improve seedlings development rate (orientation of root system and seedling crown) and for this reason its considerate most demanding and important operation. The BM requires a powerful power-source, low weight, small gauge and high maneuverability, also its PTO has a grate advantage because has two driving shafts and the driving direction can be easily change in accordance with equipment requirements, only by rotating the steering wheel.

The experimental methodology was made to validate the constructive and working parameters for every equipment incorporated, to assess the energetic parameters and also its productivity.

The first step was to evaluate the physic-mechanical terrace soil (compaction and humidity measurements at different depths). The data were taken for two land strips: on cultivated and grounded strips and are presented in Table 1. 
Table 1. Physical-mechanical soil properties of experimental field

\begin{tabular}{c|c|c|c|c|c|c|c|c}
\hline $\begin{array}{c}\text { Experimental } \\
\text { parameters/ }\end{array}$ & \multicolumn{4}{|c|}{ Grounded land } & \multicolumn{4}{c}{ Cultivated land } \\
\hline Depth [cm] & 5 & 10 & 15 & 20 & 5 & 10 & 15 & 20 \\
\hline $\begin{array}{c}\text { Average } \\
\text { compaction } \\
\text { grade [MPa] }\end{array}$ & 175.5 & 772.7 & 1299.5 & 1580 & 140 & 578.5 & 604 & 789.5 \\
\hline $\begin{array}{c}\text { Average } \\
\text { humidity [\%] }\end{array}$ & 35.2 & 35.2 & 35.4 & 35.5 & 23.3 & 27.0 & 30.6 & 33.2 \\
\hline
\end{tabular}

The FM equipment it was powered by 600 rot $\mathrm{min}^{-1}$ PTO shaft and the working speed on cultivated and also the grounded strips, are evaluated at every working cycle, so to obtain average values. The semi-trailed LM equipment has a leveling blade of $74 \times 10 \times 1000 \mathrm{~mm}$, that weights $42 \mathrm{~kg}$ and it was coupled to its towing system using a detachable fastening and removable stiffening system. This equipment is provided with: a double-edged knife to increase reliability; two adjustable transport wheels that can be adapted to road conditions and easily dismantled prior to the soil modelling commencement; the working depth adjust system $(-140 ;-70 ; 0 ;+70 ;+140 \mathrm{~mm})$ - Figure $2 \mathrm{a}$; an blade inclination system left/right towards the direction of advancement $(0,10,15,250)$ - Figure $2 b$ and an active blade width system $(1 ; 0,98 ; 0,94 ; 0,88 \mathrm{~m})$ - Figure 2c. The number of LM passes, depends of the counter-slope inclination.

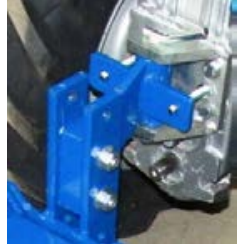

a.

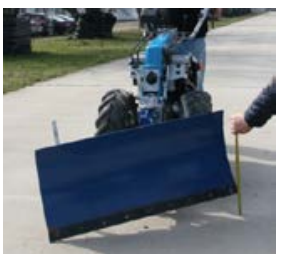

b.

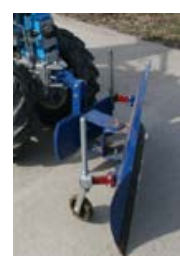

C.

Figure 2. LM working parameters adjusting systems

During the levelling process it is necessary to equilibrate the blade using additional weights of $30 \mathrm{~kg}$ in order to maintain constant the working depth. If the terrace width is larger than $1 \mathrm{~m}$, the levelling operation it is necessary to be done on at least two passes, if we take in to consideration the blade loading level.

The BM equipment weights max. $112 \mathrm{~kg}$ and is provided with two earth augers of $\varnothing$ 300 and $\varnothing 400 \mathrm{~mm}$, that can work at $300 \mathrm{~mm}$ and $400 \mathrm{~mm}$ depth. The augers are guided by the adjusting position system (designed for max. $30^{\circ}$ left and right inclination), this technical solution is patent at OSIM no. A/00705 at 05.10.2016. The auger working speed is controlled by the human operator, using the acceleration handle and the maximum rotation speed is 135 rot. min $^{-1}$. In Figure 3 and Figure 4, are presented the working parameters adjusting systems. 


\section{INTERNATIONAL SYMPOSIUM "THE ENVIRONMENT AND THE INDUSTRY", SIMI 2018, PROCEEDINGS BOOK}

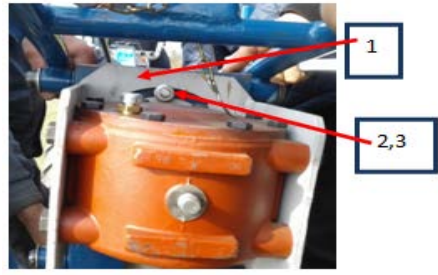

1 - positioning system, 2 - screw, 3 - nut

Figure 3. Adjusting the drill inclination

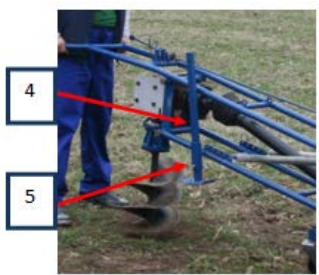

4 - position stopper, 5 - assembly elements

Figure 4. Adjusting the drilling depth

For normal working conditions (terrace counter-slope less the $15^{0}$ ) the technological process does not raise any outstanding problems, but for a counter-slope higher, the soil modelling process can be made from several passes so to dislocate a greater soil volume.

\section{Results and Discussions}

The experimental models of FM, LM and BM equipment's worked well in aggregate with $19 \mathrm{HP}$ motocultivator, in stationary and exploitation conditions (during approx. 120 hours), the experimental data obtained are presented in Table 2.

Table 2. FM, LM and BM operating parameters.

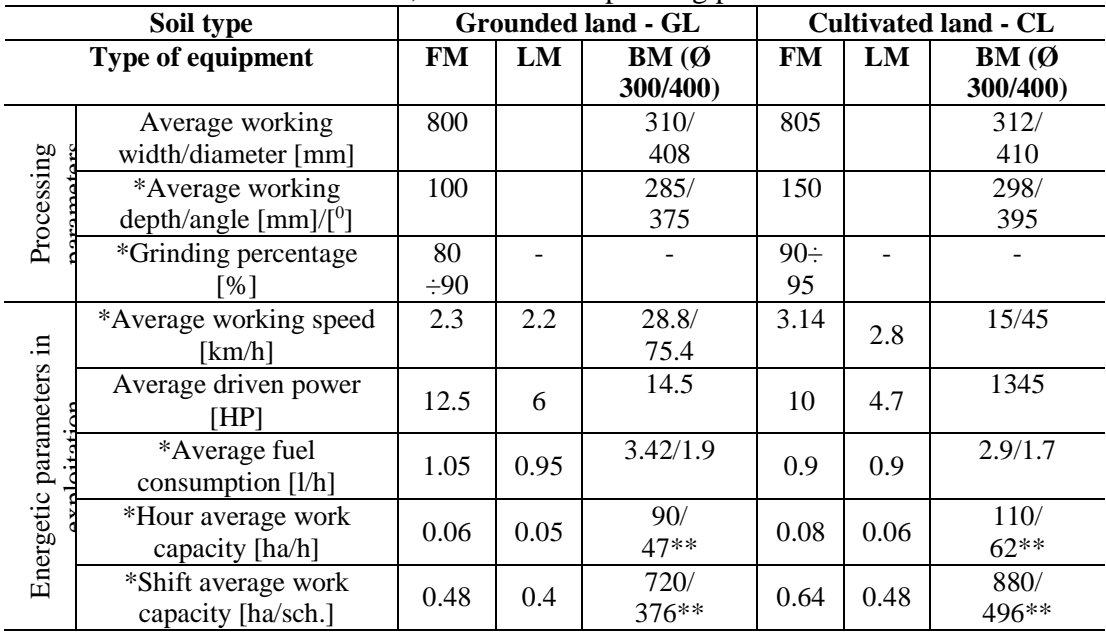

*Depends on the soil type and processing state; **The economic parameters for BM equipment's are evaluated in accordance with number holes.

At high working speeds the FM is working at a low depth and the grinding is higher, but for low speeds the depth is higher and the grinding value is lower. For this reason, the motocultivator power must be adapted to the soil type and work depth, in this way the energetic and exploitation parameters can be improved. 


\section{INTERNATIONAL SYMPOSIUM "THE ENVIRONMENT AND THE INDUSTRY", SIMI 2018, PROCEEDINGS BOOK}

The BM equipment it is in line with the specific technological requirements of forestry and pomiculture equipment's. Also, the operational parameters tested had verified one technical solutions that was patented (A0075/05.10.2016) and will be provided in the future developments with other two innovative solutions (A01001/12.12.2016 - System for rapid mounting and damping the axial shocks of the drill for making the planting holes and A0056/11.08.2017 - Deviations compensation device during the drilling process using a guided auger by parallelogram mechanism). Appling the mathematical algorithms for drilling equipment's, were determine the qualitative indices: the power consumed during the working process that is influenced by auger rotation moment (rep. the max. gear motor speed of output shaft) and by the transmission mechanical efficiency (that in our case it has the value of 0.8 ); average depth and drilling period. These indices are presented in Table 3.

Table 3. BM equipment qualitative indices for cultivated land.

\begin{tabular}{|c|c|c|c|c|c|c|c|}
\hline \multirow{2}{*}{ Qualitative indices } & \multirow{3}{*}{$\begin{array}{c}\text { Soi } \\
\text { l } \\
\text { typ } \\
\mathrm{e}\end{array}$} & \multicolumn{6}{|c|}{ Terrace counter-slope } \\
\hline & & $0^{0}$ & $15^{0}$ & $20^{0}$ & $0^{0}$ & $15^{0}$ & $20^{0}$ \\
\hline Auger diameter [mm] & & \multicolumn{3}{|c|}{300} & \multicolumn{3}{|c|}{400} \\
\hline Gear motor speed [rot/min] & - & & 135 & & & 135 & \\
\hline \multirow{2}{*}{ *Average depth $[\mathrm{cm}]$} & CL & 29.8 & 30.6 & 31.2 & 39.5 & 40.5 & 40.9 \\
\hline & GL & 28.5 & 30.26 & 31.66 & 37.5 & 38.1 & 39.6 \\
\hline \multirow{2}{*}{ *Drilling period [s] } & CL & 15 & 26 & 32 & 45 & 49.3 & 52.3 \\
\hline & $\overline{G L}$ & 28.8 & 38 & 40 & 75.4 & 76.8 & 81.6 \\
\hline \multirow{2}{*}{ *Auger advancement [cm] } & CL & 0.88 & 0.52 & 0.43 & 0.39 & 0.37 & 0.35 \\
\hline & GL & 0.44 & 0.35 & 0.35 & 0.22 & 0.22 & 0.22 \\
\hline \multirow{4}{*}{$\begin{array}{l}\text { Auger rotation moment [kgf } \\
\qquad \mathrm{cm}]\end{array}$} & & 1247.6 & 739.1 & 612.3 & 979.9 & 917.1 & 873.0 \\
\hline & CL & 3 & 1 & 0 & 9 & 6 & 9 \\
\hline & CI & 1087.5 & 875.1 & 869.8 & 971.7 & 969.2 & 948.1 \\
\hline & GL & 5 & 5 & 6 & 1 & 6 & 6 \\
\hline \multirow{2}{*}{ Average [kgf cm] } & CL & & 866.34 & & \multicolumn{3}{|c|}{923.41} \\
\hline & GL & & 944.19 & & \multicolumn{3}{|c|}{963.04} \\
\hline \multirow{2}{*}{ Power consumed [HP] } & $\mathrm{CL}$ & 2.94 & 1.74 & 1.44 & 2.31 & 2.16 & 2.06 \\
\hline & GL & 2.56 & 2.06 & 2.05 & 2.29 & 2.28 & 2.23 \\
\hline \multirow{2}{*}{ Average [HP] } & $\mathrm{CL}$ & & 2.04 & & & 2.17 & \\
\hline & GL & & 2.22 & & & 2.27 & \\
\hline
\end{tabular}

*Estimations obtained from experimental data.

The auger rotation moment depends by soil physical-mechanical properties: the global specific resistance coefficient for drilling is $2 \mathrm{kgf} . \mathrm{cm}^{-2}$ (cultivated land- CL) and of $3.5 \mathrm{kgf}^{-2} \mathrm{~cm}^{-2}$ (grounded land- GL).

The testing results of this aggregates conducted to the innovative afforestation technology homologation, the success of green infrastructure establishment of fruit trees seedling (seedling with root bale earth) that were planted in the first year of production, in this way the establishment period is shorten and the soil remediation process is shorter, fact that will lead to a medium time management environmental management and improvement of the slope degraded terrains. The equipment qualitative and energetic parameters can oscillate in the acceptable limits, especially when the equipment is used in hard working conditions. All the values presented can 


\section{INTERNATIONAL SYMPOSIUM "THE ENVIRONMENT AND THE INDUSTRY", SIMI 2018, PROCEEDINGS BOOK}

be influenced by the human factor, respectively by the physical force and the experience of the operator.

\section{Conclusions}

This research has described the technical details of a concrete solution for the afforestation of degraded lands. In a broader sense, the forestation of degraded lands contributes to the restoration of their ecological services, and, through the ecological services, to the overall sustainability. Future research should analyze whether the project was able to restore the ecosystem services of the area, including the impact on the activities carried out in the adjacent areas (agriculture etc.).

The potential beneficiaries can be: companies which carry out land reclamation, landscaping and green spaces; trading companies that carry out works in forestry, fruit growing and viticulture; forest fund management and maintenance associations, and so one.

\section{Acknowledgements}

This paper is the product of the project "Researches on substantiating an innovative technology for the afforestation of degraded slope lands”, financed by The Romanian Nucleu Programme, contract no. 8N from 09.03.2016.

\section{References}

Andronache, IC, Ahammer, H \& Teodorescu, C 2016, 'Fractal analysis for studying the evolution of forests’, Chaos, Solitons \& Fractals, vol. 91, pp. 310-318.

Chazdon, RL 2008, 'Beyond Deforestation: Restoring Forests and Ecosystem Services on Degraded Lands', Science, vol. 320, no. 5882, pp. 1458-1460.

Dutca, I \& Abrudan, IV 2010, 'Estimation of forest land-cover change in Romania, between 1990 and 2006', Bulletin of the Transylvania University of Brasov Series II: Forestry, Wood Industry, and Agricultural Food Engineering, vol. 52, pp. 33-36.

Gómez-Baggethun, E \& Barton, DN 2013, 'Classifying and valuing ecosystem services for urban planning’, Ecological Economics, vol. 86, pp. 235-245.

Jim, CY \& Chen, WY 2009, 'Ecosystem services and valuation of urban forests in China’, Cities, vol. 26, pp. 187-194.

Knorn, J, Kuemmerle, T, Radeloff, VC, Szabo, A, Mindrescu, M, Keeton, WS, Abrudan, I, Griffiths, P, Gancz, V \& Hostert, P 2012, 'Forest restitution and the protected area effectiveness in post-socialist Romania’, Biological Conservation, vol. 146, no. 1, pp. 204-212.

Kuemmerle, T, Hostert, P, Radeloff, VC, Perzanowski, K \& Kruhlov, I 2007, 'Postsocialist forest disturbance in the Carpathian border region of Poland, Slovakia, and Ukraine', Ecological Applications, vol. 17, no. 5, pp. 12791295.

Kupková, L, Bičík, I \& Najman, J 2013, 'Land Cover Changes along the Iron Curtain 1990-2006’, Geografie, vol. 118, no. 2, pp. 95-115.

La Greca, P, La Rosa, D, Martinico, F \& Privitera, R 2011. 'Agricultural and green infrastructures: The role of non-urbanised areas for eco-sustainable planning in a metropolitan region', Environmental Pollution, vol. 159, no.8-9, pp. 21932202. 


\section{INTERNATIONAL SYMPOSIUM "THE ENVIRONMENT AND THE INDUSTRY", SIMI 2018, PROCEEDINGS BOOK}

Müller, D \& Munroe, DK 2008, 'Changing Rural Landscapes in Albania: Cropland Abandonment and Forest Clearing in the Postsocialist Transition', Annals of the Association of American Geographers, vol. 98, no. 4, pp. 1-22.

Petrisor, AI \& Petrisor, LE 2017, '2010-2012 land cover and use changes in Romania - an overall assessment based on CORINE data', Present Environment and Sustainable Development, vol. 11, no. 2, pp. 119-127.

Petrisor, AI 2015, 'Using CORINE data to look at deforestation in Romania: Distribution \& possible consequences’, Urbanism Architecture Constructions, vol. 6, no. 1, pp. 83-90.

Pop, A 2012, Cercetari privind reconstructia ecologica prin impadurirea terenurilor degradate din zona Dej - Gherla, PhD. thesis, Agriculture Sciences and Veterinary Medicine University from Cluj-Napoca, Agriculture Faculty, Romania. In Romanian.

Popovici, EA, Balteanu, D \& Kucsicsa, G 2013. 'Assessment of changes in land-use and land-cover pattern in Romania using CORINE land cover database', Carpathian Journal of Earth and Environmental Sciences, vol. 8, no. 4, pp. 195-208.

Untaru, E 2010, 'Premise privind impadurirea terenurilor degradate in conditiile schimbarilor climatice generate de incalzirea globala', Revista padurilor, no.1

Watson, R \& Zakri, AH 2005, Ecosystems and Human Well-being. Synthesis, Island Press, Washington, DC, USA.

Young, RF 2010, 'Managing municipal green space for ecosystem services', Urban Forestry \& Urban Greening, vol. 9, pp. 313-321.

Zakri, AH \& Watson, R 2003. Ecosystems and Human Well-being. A Framework for Assessment, Island Press, Washington, DC, USA. 